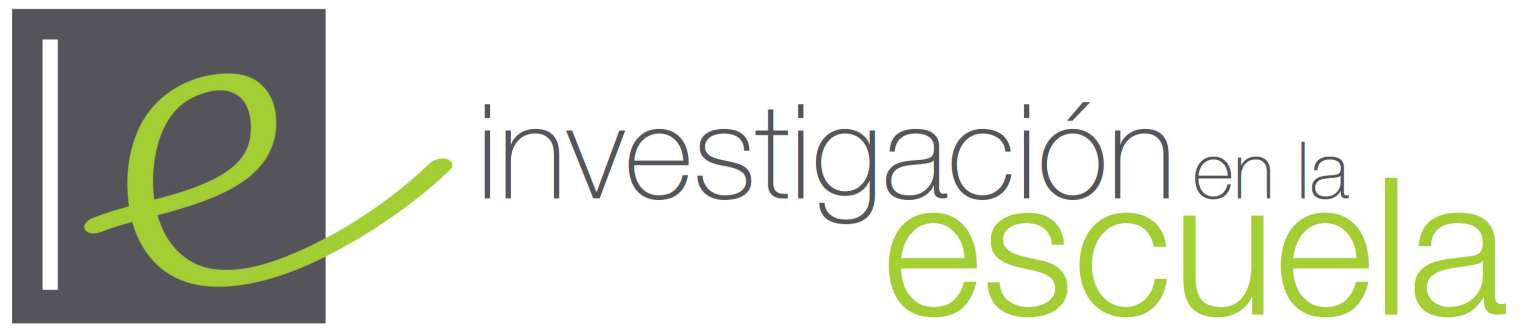

Revista internacional de investigación e innovación educativa

\title{
La educación patrimonial como medio para la inclusión social: análisis de una experiencia didáctica ${ }^{1}$
}

\author{
Elisa Arroyo Mora y Belén Crespo Torres² \\ Universidad de Huelva \\ España
}

Citación: Arroyo Mora, E. y Crespo Torres, B. (2019). La educación patrimonial como medio para la inclusión social: análisis de una experiencia didáctica. Investigación en la Escuela, 98, 62-75. doi: http://dx.doi.org/10.12795/IE.2019.i98.05

Resumen: Este trabajo presenta un estudio basado en una experimentación de una propuesta educativa, de educación patrimonial, desarrollada en una asociación ubicada en un contexto en riesgo de exclusión social. Con la experimentación de este diseño didáctico, que utiliza el patrimonio local como recurso y como contenido y que se basa en una perspectiva constructivista y utiliza un itinerario didáctico como estrategia, se comprueba el cambio de concepciones de un grupo de chicos y chicas de una barriada del pueblo Minas de Riotinto acerca del patrimonio de su localidad. A través de una entrevista colectiva, la observación directa y participante y un cuestionario de preguntas abiertas sobre diferentes aspectos abarcados con la educación patrimonial, se describen los cambios

\footnotetext{
${ }^{1}$ Este trabajo se enmarca en el Proyecto de Investigación "Educación Patrimonial para la inteligencia territorial y emocional de la ciudadanía” (EPITEC) financiado por el Ministerio de Economía y Competitividad EDU20145-67953-P (MINECO/FEDER) y en el Centro de Investigación en Pensamiento Contemporáneo e Innovación para el Desarrollo Social (COIDESO) de la Universidad de Huelva.

${ }^{2}$ Las autoras son investigadoras del Grupo de Investigación DESYM "Formación inicial y desarrollo profesional del profesorado" (HUM-168).
} 
conceptuales y actitudinales de los participantes, analizados bajo una metodología cualitativa y utilizando un sistema de categorías que se basa en conceptos de patrimonio, identidad e inteligencia emocional, territorial y social. Tras el desarrollo del estudio, se pueden extraer diversas conclusiones en torno a la necesidad de propiciar situaciones de aprendizaje en entornos no formales utilizando el patrimonio local como recurso para el acercamiento de los niños y niñas a valores de justicia social, solidaridad y empatía cultural y para disminuir en la medida de lo posible las situaciones que provoquen exclusión o aislamiento social de ciertos colectivos.

Palabras clave: "Educación patrimonial"; "experimentación educativa"; "educación no formal”; "emociones"; "estudio cualitativo"; "inclusión social"; "itinerario didáctico"; "patrimonio local".

\section{Heritage education to social inclusion: analysis of a teaching experience}

Abstract: This paper presents a study based on an educational experimentation of a didactic proposal of non-formal education of heritage education in an association located in a context at risk of social exclusion. We use the experimentation of this didactic design, which uses the local heritage as a resource and as a content and that is based on a constructivist perspective and uses active methodological strategies, to describe the change of conceptions of a group of boys and girls from a neighborhood of the town known as Minas de Riotinto, about the heritage of your locality. Through a collective interview, direct and participant observation and a questionnaire of open questions about different aspects covered by heritage education, the conceptual and attitudinal changes of the participants are described, analyzed under a qualitative methodology using a system of categories that based on concepts of heritage, identity and emotional, territorial and social intelligence. When the development of the study finished, several conclusions can be drawn about the need to promote learning situations in non-formal environments using local heritage as a resource for the approach of children to values of social justice, solidarity and cultural empathy and to reduce as much as possible the situations that cause exclusion or social isolation of certain groups.

Key words: "Heritage education"; "educational experimentation"; "non-formal education"; "emotions"; "qualitative study"; "social inclusion"; "educational path"; "local heritage".

\section{L'éducation patrimoniale comme moyen d'inclusion sociale: Analyse d'une expérience didactique \\ Resumè: Cet ouvrage présente une étude basée sur une expérimentation pédagogique d'une} proposition didactique d'éducation non formelle en éducation au patrimoine au sein d'une association située dans un contexte de risque d'exclusion sociale. Avec l'expérimentation de cette conception didactique, qui utilise le patrimoine local comme une ressource et un contenu, et qui repose sur une perspective constructiviste et utilise des stratégies méthodologiques actives, le changement de conceptions d'un groupe de garçons et de filles d'un quartier de la ville est vérifié Minas de Riotinto sur le patrimoine de votre localité. À travers un entretien collectif, une observation directe et participante et un questionnaire de questions ouvertes sur les différents aspects couverts par éducation au patrimoine, les changements conceptuels et comportementaux des participants sont décrits et analysés selon une méthodologie qualitative utilisant un système de catégories qui: sur la base de concepts de patrimoine, d'identité et d'intelligence émotionnelle, territoriale et sociale. Après le développement de l'étude, plusieurs conclusions peuvent être tirées sur la nécessité de promouvoir des situations d'apprentissage dans des environnements non formels, en utilisant le patrimoine local comme une ressource pour l'approche des enfants en matière de valeurs de justice sociale, de solidarité et d'empathie culturelle. réduire autant que possible les situations d'exclusion ou d'isolement social de certains groupes. 
Mots-clés: "Éducation au patrimoine”; “expérimentation educative”; "éducation non formelle”; "émotions"; "étude qualitative"; "inclusion sociale"; "itinéraire didactique"; "patrimoine local".

\section{Introducción y fundamentación teórica}

El presente trabajo muestra una experimentación didáctica de educación patrimonial en una asociación ubicada en una barriada del pueblo Minas de Riotinto (Huelva), contexto en riesgo de exclusión social, a la que acuden numerosos niños y niñas de distintas edades. Este estudio pretende destacar y reafirmar la utilización de la didáctica del patrimonio desde el ámbito de la educación no formal para el fomento de actitudes de respeto y tolerancia, de valoración y cuidado de los propios elementos patrimoniales y de un pensamiento más crítico y consciente de los problemas socioambientales, con el fin de formar ciudadanos competentes, justos y solidarios.

Para educar desde el patrimonio, éste debe interpretarse desde una perspectiva holística, considerándolo, según Cuenca (2002), como el conjunto de todos los elementos que se convierten en los símbolos que configuran los referentes identitarios de las comunidades, representando los aspectos culturales de relevancia del pasado y del presente como fuertes básicas para el conocimiento social. El patrimonio es, en este sentido, un recurso social; somos nosotros mismos, pues en su dimensión de espejo social reconocemos la creatividad, autoestima y capacidad de respeto a lo diferente de un pueblo (Fernández, 2005).

La idea de patrimonio es descrita por González Monfort (2007) como un constructo social atribuido a grupos que reconocen voluntariamente elementos y manifestaciones, como legado para comprender sus raíces, su presente y la expectativa de futuro. El propio patrimonio es un ingrediente fundamental para el sentido de identidad, ya que la pérdida de los orígenes conlleva inevitablemente la pérdida de la identidad, o lo que es lo mismo, la sensación de pertenencia a un determinado colectivo social (Cuenca, 2014), por lo que es una temática que debe abordarse en comunidad, promoviendo valores que ensalcen al propio territorio, lo protejan y lo difundan.

Los elementos patrimoniales, además, se deben utilizar para promover el pensamiento crítico sobre el mundo que nos rodea, aparte de los objetivos en cuanto a conocimiento, conservación y apreciación del patrimonio (Jiménez, Cuenca y Ferreras, 2010).

La educación patrimonial es, por esto, una herramienta clave que conecta, tal y como expresa Cuenca (2014), el patrimonio con los intereses y preocupaciones de la sociedad, de forma que patrimonio y sociedad se aporten recíprocamente. Ya en los currículos oficiales de todas las etapas educativas aparecen objetivos y contenidos de educación patrimonial, pues es una actuación no solo necesaria sino imprescindible porque opera sobre esa relación entre bienes y personas, que son la propia esencia del patrimonio (Fontal e Ibáñez, 2015).

Sin embargo, la educación patrimonial va más allá de la dimensión escolar, pues tiene lugar en ámbitos de educación no formal e incluso informal y contribuye a diseñar instrumentos de mediación destinados a la sociedad, para reflexionar sobre cómo el paisaje pasa de escenario a objeto de conocimiento (Martín y Cuenca, 2015). En el contexto de la educación no formal, como es el caso de la asociación donde se desarrolla este estudio, se debe ofrecer a la población la información necesaria que ayude a comprender ese patrimonio con una mirada informada (Castro y López, 2018).

Para diseñar un programa de actividades en términos didácticos del patrimonio en la educación no formal, es básico abordar el análisis de concepciones, expectativas, conocimientos y necesidades, (Martín y Cuenca, 2015), de aquellos que van a recibir dicha formación y de la sociedad en general. 
Seguido a esto, tal y como Peñalba (2010) afirma, es responsabilidad del educador o gestor patrimonial ayudar al discente a interpretar los significados y valores patrimoniales por la importancia de generar procesos de identidad colectiva y de construir una memoria cultural colectiva a partir del patrimonio y para propiciar una puesta en valor del patrimonio, inculcando actitudes éticas de respeto y corresponsabilidad en la conservación de la propia herencia cultural. Esto es solo posible mediante el diseño de actividades que permitan que los estudiantes trabajen activamente en la construcción de conocimientos, incluyendo actividades basadas en la resolución de problemas sociales complejos y reales en torno al patrimonio en las que el alumnado tiene un rol activo en sus propios aprendizajes (Melgar y Donolo, 2011).

Una estrategia didáctica idónea para educar desde el patrimonio es la utilización de las salidas culturales y visitas a museos y centros de interpretación. Sin embargo, estas visitas no pueden ser aisladas, sino que deben ser selectivas, teniendo en cuenta la edad y las características del público. En ellas, el alumnado debe tener un papel protagonista, no ser receptores pasivos que sólo escuchan al profesor o guía (Llobet y Valls, 2003). Así, la experimentación que presenta este trabajo gira en torno a un itinerario didáctico por la localidad en el que, con la ayuda de las investigadoras y una guía, los niños y niñas contribuyen a la narración de la historia de su propio pueblo a partir de lo que ya saben por su experiencia previa. De esta forma, se construyen aprendizajes significativos a partir de sus ideas previas, fomentando la motivación intrínseca del alumnado y potenciando sus competencias emocionales, esenciales para el desarrollo integral de la personalidad (Bisquerra y Pérez-Escoda, 2012).

Así, la educación patrimonial conjuga las relaciones entre las emociones y el territorio en la construcción de identidades, centrando el trabajo con las emociones en abordar la empatía, el respeto, la convivencia y el bienestar individual y comunitario (Miedes, Sánchez y Moreno, 2014). Es importante trabajar cuidadosamente la cuestión emocional dentro del patrimonio debido a que las emociones interculturales son las que se experimentan cuando se está con personas de otra etnia, color, cultura, lengua, religión, etc., y, en función a cómo se regulen dichas emociones, pueden facilitar o dificultar la convivencia. Las actitudes prosociales son las que hacen fáciles las relaciones interpersonales, como la empatía y la capacidad de escucha. Por tanto, es esencial trabajar estas habilidades sociales en el alumnado desde los primeros años de vida (Bisquerra y Pérez-Escoda, 2012). Todo esto conduce a la construcción de autonomía moral por parte del alumno, unido a un desarrollo de capacidades cognitivas, como el pensamiento crítico, la solidaridad y la autonomía intelectual, formando a una persona que se rige por criterios de justicia, dignidad personal y autorregulación emocional (Cuenca y Estepa, 2006).

La educación patrimonial es una disciplina muy adecuada, además, para trabajar desde la educación no formal en contextos en riesgo de exclusión social, pues ensalza y respeta la importancia del individuo en su dimensión individual, pero también social (Pablos y Fontal, 2018), haciendo referencia a las relaciones en las que el centro es la persona, sin connotaciones ni expectativas. Es esencial, con este fin, tal y como apunta García (2014), hacer sentir a estos sectores de las comunidades que el patrimonio les pertenece y que ellos forman parte del patrimonio por su experiencia con él a lo largo de su trayectoria de vida, dándole consciencia de su capacidad de dejar huella en él y su deber de compartirlo con los demás.

La inclusión social está inmersa en los procesos de patrimonialización, pues la educación patrimonial se dirige a un modelo social inclusivo ajustado a las necesidades sociales, en el que existen patrimonios diferentes desde la perspectiva de cada sector de la sociedad y en el que la diferencia se entiende como un elemento vinculante porque el hecho de ser diversos es lo que nos une (Marín, 2014).

La propuesta didáctica que se desarrolla en este estudio se basa en la justificación de todos los autores previamente mencionados, pues pretende que, desde la educación patrimonial, sacando 
provecho a todas las posibilidades con las que cuenta el pueblo Minas de Riotinto (Huelva), se fomenten unas determinadas habilidades sociales en los niños y niñas de un contexto socio-cultural medio-bajo y se desarrolle cierto sentimiento de pertenencia a su municipio y a su comunidad, a través de un trabajo práctico que promueva gran cantidad de aprendizajes sobre el lugar en el que viven al tiempo que se les enseña a disfrutar de todo lo que tienen. A medida que se desarrolla este trabajo, se irán promoviendo actitudes prosociales que pretenden disminuir el riesgo de exclusión social de las personas que acuden a la asociación en la que se lleva a cabo la intervención.

\section{Contexto y concepciones}

La investigación educativa que presenta este estudio se ha llevado a cabo para conocer el cambio de concepciones y emociones de un grupo de niños y niñas de la asociación conocida como "Unidos por el Alto", ubicada en la barriada El Alto de la Mesa del municipio de Minas de Riotinto, cuyas características socioculturales de sus habitantes la sitúan como un contexto en riesgo de exclusión social e incluso con cierto grado de marginalidad. Esto es debido a la continuidad hasta el presente de la finalidad con la que dicho barrio se edificó, pues se construyó en el siglo XIX para alojar a trabajadores inmigrantes vinculados a las tareas de arranque y transporte mineral, habitando chozas y chabolas con pocas garantías de bienestar social. En la actualidad, gran parte de la barriada está compuesta por familias jóvenes, humildes y, en su mayoría, desfavorecidas, con bajo nivel de estudios y en situación de desempleo, o familias itinerantes procedentes de América del Sur o del este de Europa, recientemente alojadas para desempeñar labores en una de las grandes empresas de recolección de frutas, destacadas en la comarca minera.

Como consecuencia de esta realidad, los participantes de esta experimentación al tener diferentes edades y proceder de distintas zonas, aportan gran riqueza cultural a la presente investigación. La muestra es de un total de 18 integrantes, siendo estos, en su mayoría, niños y adolescentes, entre 4 y 17 años, con necesidades específicas de apoyo educativo (algunos presentan dificultades específicas de aprendizaje, otros, de incorporación tardía al sistema educativo e incluyendo a un chico con necesidades educativas especiales de 25 años de edad).

Para averiguar el cambio de concepciones de los participantes tras la puesta en práctica de la intervención que corresponde a la experimentación didáctica, se ha utilizado una metodología cualitativa con la que se ha analizado la información previa recabada, obtenida con una primera entrevista colectiva semi-estructurada y la producción de dibujos y su exposición oral, con la que se averiguan las concepciones iniciales, así como las variaciones producidas en cuanto a ideas y a emociones durante y tras las sesiones, registradas mediante grabaciones de audio y vídeo desde una observación participante y con un cuestionario de preguntas abiertas en relación a la procedencia, historia, importancia y valoración de los elementos patrimoniales de su localidad completado en la última sesión.

En cuanto a las concepciones que presentan los participantes, antes del desarrollo de la experimentación didáctica, sobre el concepto de patrimonio, se puede afirmar que la gran mayoría de ellos manifiestan no conocer el término o no haberlo escuchado antes. Sin embargo, cuando se invita a la reflexión de dicho concepto a través de diversas cuestiones y ejemplos, sin las habituales presiones de calificación, comienzan a plasmarse las primeras ideas sobre los elementos patrimoniales. Algunos de los niños y niñas, sin más, confunden incluso el término patrimonio con otros de parecida sonoridad: “¿Qué es el patrimonio?” Eso es cuando un hombre y una mujer se casan (Participante 2). Por otra parte, los de mayor edad intentan buscar el concepto en sus dispositivos móviles, convencidos de que el término de patrimonio se asocia con la herencia desde el punto de vista capital. 
Cuando se les pregunta dónde han escuchado anteriormente el vocablo patrimonio, la gran mayoría permanece en silencio, mientras que algunos afirman haberlo oído en el colegio: Me lo ha dicho mi maestra Chari en Sociales (Participante 3). Eso es algo de un edificio, ¿no? (Participante 4). Estas respuestas denotan la falta de conceptualización del término y de las que se puede advertir cierta perspectiva monumentalista del mismo.

No obstante, la matización de una chica a esta última afirmación sí deja prever cierta perspectiva identitaria y simbólica del patrimonio de su localidad: Es un edificio que identifica a nuestro pueblo, ¿no? (Participante 6). Con esta frase se señala una ligera idea del concepto y del vínculo con la identidad que se pretende potenciar con este estudio.

Además de estas preguntas iniciales en torno a la temática, para averiguar sus ideas previas, se mostraron una serie de imágenes sobre los elementos patrimoniales destacados en la comarca, averiguando que todos los niños y niñas reconocieron de inmediato los elementos representados y fueron capaces de describirlos.

Para concluir con la recogida de concepciones de esta primera sesión de la propuesta, los participantes produjeron dibujos sobre aquello que consideraban importante de su pueblo, a elección libre, para comprobar la perspectiva de patrimonio que tenían y si hacían alguna distinción en cuanto a la tipología del mismo. Los integrantes de la asociación, en su mayoría, reflejaron de forma algo estereotipada algunos elementos de la localidad, sin plasmar tal vez aquellos con los que sí establecen en mayor grado vínculos emocionales e identitarios.

Tras la obtención de esta información inicial a través de diversas técnicas, se considera que los participantes son conscientes de todos los elementos señalados de su pueblo y que conocen parte de la historia que se desarrolló en él, sin asociarlo directamente con la terminología que se pretende trabajar. Por otro lado, es destacable que, a pesar de tener ciertas nociones sobre el patrimonio de su entorno, estos no muestran demasiado interés y preocupación por él, tal vez a consecuencia de la cotidianidad y costumbre de estos elementos y de una falta de didáctica patrimonial. Es por esto que se denotan carencias en cuanto a la concienciación de las problemáticas relacionadas con el patrimonio y a su implicación en su territorio.

En lo relativo a las interacciones sociales en el grupo, se pudo percibir un fuerte y positivo sentimiento de unión entre los habitantes del barrio y cierto orgullo a pertenecer a él, con oraciones como El Alto es una gran familia (Participante 4) o Es que nosotros somos como un banco y, si una pata falla,... (Participante 6). Sin embargo, también se aprecia la falta de relación o contacto de los integrantes de la asociación con las personas de otras ubicaciones del municipio más allá de las horas que permanecen en la escuela, lo que da sensación de un cierto aislamiento de la barriada respecto al resto del pueblo.

Asimismo, quedan registradas, de forma esporádica, ciertas afirmaciones con tintes xenófobos y de rechazo a la llegada de visitantes o inmigrantes al pueblo: No quiero que venga gente de fuera porque vienen a robarnos (Participante 2). Este tipo de comentarios podrían ser reflejo de imitación de modelos con bajo nivel de cultura y son, sin duda, la repetición de prejuicios sin reflexión alguna.

\section{Diseño y experimentación de la propuesta}

La propuesta didáctica de la experimentación presentada parte de la base de que solo mediante experiencias en las que los estudiantes sean protagonistas activos del proceso de enseñanza-aprendizaje se propicia el aprendizaje significativo a través de situaciones en las que se aborden los contenidos desde la perspectiva constructivista, con actividades lúdicas, amenas, divertidas y funcionales, que les permitan extrapolar todos las aprendizajes adquiridos a situaciones de la vida cotidiana. 
En esta línea, ya Estepa (2001) señalaba la necesidad de propiciar situaciones en las que el alumnado tuviera un contacto directo con los elementos patrimoniales y en las que tuviera lugar cierto grado de experiencia con estos para fomentar en verdadero cambio de actitud del niño o niña. Por esto, la experimentación didáctica presenta una intervención educativa que gira en torno a una salida cultural, en la que se proyectan directamente las vivencias de los discentes sobre los elementos patrimoniales emblemáticos de su entorno.

Para favorecer el desarrollo de las competencias emocionales (Bisquerra y Pérez-Escoda, 2012) de los chicos y chicas y, en este caso, aprovechando el lugar en el que viven nuestros participantes, a través de un itinerario didáctico donde se podrán visualizar todos los elementos patrimoniales, se trabajará el concepto de patrimonio desde una perspectiva sistémica.

El itinerario seguido fue escogido minuciosamente para garantizar la admiración de un entorno donde se integran diferentes tipos de patrimonio desde una perspectiva holística e integral, incluyendo actividades reflexivas e indagatorias antes, durante y después de la salida. Este tipo de propuestas metodológicas que parten de la investigación e indagación como técnica de aprendizaje y de un centro de interés a través del que se desarrollan los contenidos culturales y sociales, donde se vivencian los aprendizajes, despiertan el interés y la motivación de los estudiantes. Este tipo de planteamientos no solo favorece la adquisición y el proceso de comunicación, sino que promueve el desarrollo de habilidades emocionales y afectivas, de investigación y búsqueda, sociales, cognitivas, físicas y de resolución de problemas. De este modo, se van propiciando situaciones que posibilitan formar a seres competentes, finalidad que se contempla tanto en el Decreto 97/2015, de 3 de marzo, por el que se establece la ordenación y el currículo correspondiente a la Educación Primaria en la Comunidad Autónoma de Andalucía, como en la Orden ECD/65/2051, de 21 de enero, por la que se describen las relaciones entre las competencias, los contenidos y los criterios de evaluación de la Educación Primaria, la Educación Secundaria Obligatoria y el Bachillerato. Estas competencias que se potencian en el desarrollo de la propuesta educativa se garantizan teniendo en cuenta el modelo de las inteligencias múltiples (Gardner, 2001), fomentando habilidades de diversa índole, y los modelos de pensamiento, que permiten formar a personas justas, empoderadas y críticas, capacitadas para construir su propio conocimiento a través de la investigación y, así, contribuir con sus acciones al cambio social del entorno en el que viven.

\section{Resultados de la investigación y discusión}

Al comenzar el estudio, tal y como se ha expresado con anterioridad, los niños y niñas mostraban vagos conocimientos sobre el concepto de patrimonio. Además, probablemente como consecuencia de la falta de interés que provocan los elementos y hechos cuando estos se vuelven cotidianos y cuando no se educa desde ellos, los chicos y chicas de la asociación no acusaban demasiado los actos vandálicos ni aquellas acciones que dañasen el territorio propio, más bien mostraban indiferencia aunque sí tuvieran la percepción de defender fehacientemente a su barrio y su pueblo.

Tras el desarrollo del itinerario didáctico en el que se pudieron observar detalles que antes habían pasado desapercibidos para ellos y en el que se reflexionó sobre las sociedades del pasado y del presente, se advirtieron cambios en los discursos de los participantes, sobre todo, en cuestiones de índole social.

Para analizar toda la información recogida en las transcripciones de audio y vídeo, se utilizó un sistema de categorías que centraba sus conceptos clave en torno al patrimonio, a los vínculos identitarios establecidos con el mismo, a su concienciación con los problemas socioambientales 
relativos al territorio, a sus relaciones sociales y emociones y a las características de la metodología de enseñanza de la propuesta experimentada.

En cuanto a la categoría de concepto de patrimonio, incluyendo las subcategorías de perspectiva y tipología del patrimonio, se ha podido comprobar que los niños y niñas de la asociación pasaron de considerar elemento patrimonial únicamente aquello con carácter monumental a tenerlo en cuenta desde una perspectiva simbólica-identitaria, como denotan algunas respuestas del cuestionario a la pregunta "¿Qué es el patrimonio para ti?" que aludían a aquello que nos representa a nosotros y a nuestro pueblo (Participante 4), dándole, aunque de forma muy general y básica, cierta perspectiva holística al patrimonio. Esto sucede gracias a que, como se establece en la Orden, de 17 de marzo, se da una contextualización de los aprendizajes a través de la consideración de la vida cotidiana y de los recursos del medio cercano como un instrumento para relacionar la experiencia con los aprendizajes.

Por otra parte, en lo relativo a aquellas relaciones que se establecieron con respecto al patrimonio, en principio se puede percibir que se forman vínculos con ciertas representaciones estereotipadas (como la Corta Atalaya o la cruz de Santa Bárbara), más que con aquello que verdaderamente les puede identificar, como podría ser algún elemento significativo de su barriada o alguna costumbre relevante para ellos. Además, su identidad parece estar constituida por elementos territoriales y emocionales, sin que se produzca una profunda reflexión sobre el significado de los elementos para ellos.

Sin embargo, este experimento educativo sí ha contribuido a la mejora de otros aspectos relacionados con la concienciación de su relación de reciprocidad con su entorno y su patrimonio y con su percepción de ciertas problemáticas sociales. Por ejemplo, tras el desarrollo de las sesiones, los chicos y chicas hablan del ejemplo como mecanismo para mostrarle al resto de personas de su barriada y de su pueblo qué actos perjudican y cuáles benefician a su entorno y ya identifican y rechazan con algo más de intensidad aquellas acciones que dañan los elementos patrimoniales, como tirar basura, hacer grafitis, contaminar... (Participantes 7, 3 y 6), pues, tal y como apunta Ferreras (2013), la población va adquiriendo conciencia de las consecuencias que conlleva el descuido y falta de protección de entorno que le rodea e incrementando su implicación ante los problemas socioambientales y patrimoniales que existen gracias al trabajo de la educación patrimonial.

Además, la visita a los diferentes lugares de interés de la localidad, las explicaciones de las investigadoras y la guía cultural y los diálogos y procesos de reflexión a los que se llegó a través de ellos, han llevado a los participantes a tomar conciencia de la necesidad de valorar, proteger y difundir su propio patrimonio y las implicaciones socioeconómicas que ello conlleva: Es importante que venga gente de fuera al pueblo porque dan dinero al pueblo (Participante 10).

Del mismo modo, sí se aprecia una cierta transformación en cuanto a sus ideas sobre las diversas problemáticas sociales. Esto sucede ya que la educación patrimonial es una disciplina plenamente inclusiva porque desde ella se abordan las relaciones que el sujeto establece con los bienes (Pablos y Fontal, 2018). Si, en una primera sesión, un chico mostraba su rechazo a la inmigración, producto de prejuicios heredados, en una de las partes de la salida cultural, concretamente la guiada por el antiguo club donde solo los hombres blancos podían entrar, los niños y niñas hacen alusión a la injusticia que esto suponía y muestran gran rechazo al machismo de la época.

Sin embargo, y a pesar de, como se mencionó en apartados previos, la fuerte unión existente entre las personas de la barriada y de la asociación, se puede percibir, por las palabras y actitudes de los niños y niñas, cierto aislamiento del resto de la población. La mayoría de ellos nunca había podido entrar en lugares como el barrio y el club que construyeron los directivos ingleses de las minas y que ahora forma parte de uno de los lugares más exclusivos del pueblo. Las condiciones desfavorables que se reúnen en esta barriada provocan que haya una gran desconexión con otras 
zonas de la localidad por diferentes motivos. De hecho, una chica expresa: Una niña de mi clase dice que le da miedo venir al Alto (Participante 4), resaltando el rechazo que otras personas muestran hacia este lugar. Esta declaración demuestra que la inclusión es aún un reto por conseguir, por el que se debe seguir trabajando para la consecución de una calidad educativa e inclusiva del patrimonio por y para las personas (Marín, García, Vicent, Gillate, Gómez, 2017).

La última categoría de análisis de los resultados es la relativa a las estrategias metodológicas empleadas en las sesiones de la experimentación educativa descrita. En este sentido, se aprecia que el patrimonio del pueblo Minas de Riotinto es, en todo momento, un contenido didáctico específico sobre el que gira todo el programa educativo. Además, en él se establecen diferentes tipos de aprendizaje en varias dimensiones, como la cognitiva, cuando se introducen conceptos y términos nuevos; la emocional, apelando a las experiencias pasadas de los estudiantes con los elementos patrimoniales; y social, provocando la toma de conciencia de la necesidad de construcción de la identidad individual y colectiva en torno al patrimonio de su propio pueblo. En el esquema se especifican todos los aspectos en los que consiste la metodología empleada en la intervención (Figura 1).

Una metodología activa que parta de las ideas y experiencias del alumnado siempre conlleva, en mayor o menor medida, un cambio profundo en sus conocimientos y emociones, pues promueve que se produzcan aprendizajes significativos. La educación patrimonial debe partir de unas consideraciones metodológicas básicas que aseguren la promoción de valores cívicos, éticos y afectivos que Cuenca y Estepa (2006) relacionan con la defensa y protección de los elementos patrimoniales del entorno cercano y de escalas territoriales mayores, así como de costumbres y tradiciones que fomenten el sentimiento de identidad cultural de los ciudadanos, e, igualmente, de la diversidad cultural, con lo que ello implica en cuanto al respeto, valoración, empatía con otras comunidades, y de relación con la naturaleza en pro de un desarrollo sostenible de la sociedad. La educación emocional proporciona, en este sentido, herramientas para derribar prejuicios y estereotipos que discriminan a ciertos sectores de la sociedad. Es por este motivo que encontramos la necesidad de que los objetivos y contenidos del patrimonio no queden relegados a la normativa y tengan tan poca aplicación real en el ámbito de la educación formal y no formal, pues, como indica Marín (2014) en su estudio, no existe modelo educativo sólido que oriente las prácticas de educación patrimonial y diversidad. A pesar de esto, estudios de Pablos y Fontal (2018) afirman el aumento de diseños de trabajo inclusivos en entornos educativos no formales, lo cual está propiciando un cambio de perspectiva al mostrar que otras prácticas son posibles. 


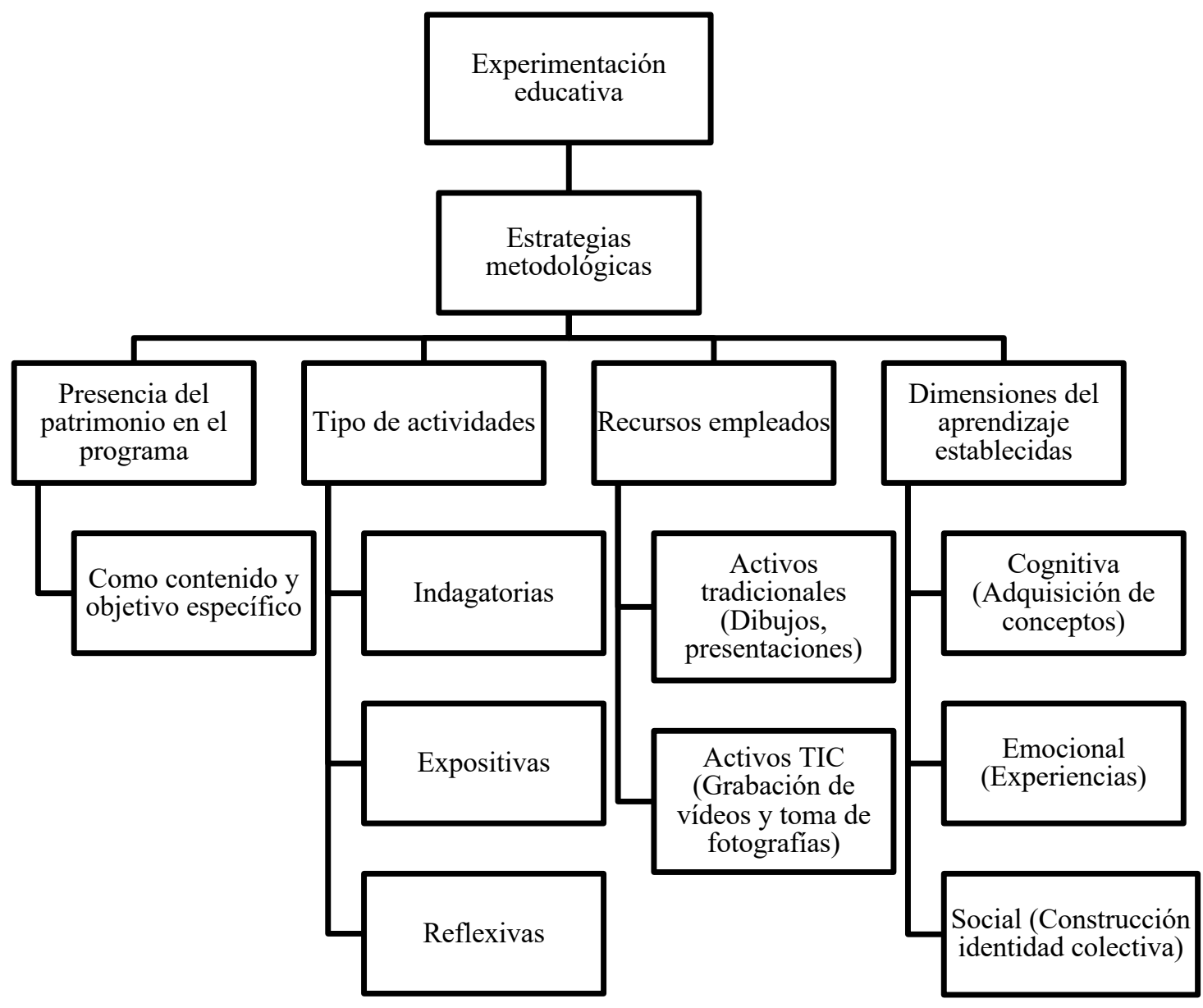

Figura 1. Esquema de la categoría metodología de enseñanza

\section{Conclusiones e implicaciones educativas}

Tras la experimentación de la propuesta didáctica presentada, una vez que se ha valorado y reflexionado sobre toda la información recabada, se han podido extraer una serie de conclusiones e implicaciones educativas.

Una de las más destacadas es el cambio de concepciones sobre los elementos patrimoniales que se produce de los momentos previos a los posteriores a la intervención. Con sus concepciones iniciales demostraban conocer los elementos patrimoniales de su municipio, sin relacionarlo directamente con el concepto de patrimonio, desde una perspectiva monumentalista, probablemente provocada principalmente por las imágenes que se dan en los libros de texto del área de Ciencias Sociales. Tras el análisis de las respuestas posteriores a la propuesta didáctica, los chicos y chicas reflejan, a través de sus explicaciones, la modificación del término patrimonio que se ha producido en ellos, considerándolo desde una perspectiva cercana a la integral y holística, así como el desarrollo de vínculos emocionales e identitarios, en un grado básico, con los elementos patrimoniales de su localidad, valorando y justificando la importancia de estos en la misma. Además, los participantes manifiestan verbalmente las acciones que benefician y perjudican al desarrollo del pueblo, reflejando 
un aumento en su grado concienciación con respecto a su capacidad de actuación en su propio territorio.

Por otra parte, la utilización de estrategias metodológicas activas en torno a visitas culturales despierta el interés, la motivación y la implicación del alumnado en el aprendizaje. De este modo, se podría afirmar que este tipo de metodología contribuye a un cambio en la valoración que los estudiantes hacen del patrimonio, conectando sus conocimientos con sus emociones y aportando significado y utilidad a los aprendizajes. Esta es una forma también de conectar a la población con el patrimonio en torno a los problemas socioambientales que se producen en su entorno y concienciarla de su capacidad de acción y cambio en el mismo.

La educación patrimonial, tal y como expone Hernández (2003), es un espacio interdisciplinar por definición desde el cual se conecta la geografía, el arte, la historia, la ciencia, la técnica, etc. Esto convierte a los elementos patrimoniales en un marco idóneo para plantear la complejidad de la realidad y la importancia de los conocimientos integrados para conocerla y entenderla. Desde esta perspectiva, la cual se ha tenido presente en el diseño e implementación de la experimentación de esta propuesta didáctica, la educación patrimonial es, además de un contenido específico, un vehículo idóneo para trabajar de forma integrada todos los contenidos del currículo y potenciar las competencias clave que se desarrollan en el mismo y para fomentar actitudes de respeto, valoración y tolerancia, esenciales para reducir el riesgo de exclusión social de ciertos colectivos.

Por otro lado, tal y como se puede apreciar a lo largo del presente texto, la intervención llevada a cabo desde un ámbito no formal ha resultado satisfactoria en relación a los objetivos propuestos, lo cual puede demostrar que, siempre que la variedad de agentes a participar trabajen en estrecha coordinación, se podrán obtener resultados interesantes, independientemente del ámbito desde el que se trabaje.

No obstante, cabe destacar que una limitación importante de este trabajo de investigación es el obstáculo temporal, ya que, como se expone en líneas anteriores, la intervención educativa, en este caso, solo se aborda desde el ámbito no formal de una asociación, cuando lo ideal sería extrapolar la investigación de esta temática a la escuela y trabajarla de forma transversal a lo largo de un trimestre, bajo la coordinación del equipo docente de todos y cada uno de los niveles.

Se considera, sin embargo, que el estudio realizado puede resultar interesante al incorporar ciertas novedades, tales como el trabajo de la inteligencia emocional a través de los elementos patrimoniales o la educación patrimonial como recurso didáctico para integrar en su entorno e implicar a aquellos ciudadanos que se encuentren en situaciones desfavorecidas o en riesgo de exclusión social.

\section{Referencias}

Castro, B. M.; López, R. (2018). Patrimonio cultural y competencias sociales: bases para una propuesta de intervención didáctica en Portomarín. Educatio Siglo XXI, 36 (1), 129-148.

Cuenca, J. M. (2002). El patrimonio en la didáctica de las Ciencias Sociales. Análisis de concepciones, dificultades y obstáculos para su integración en la enseñanza obligatoria. Huelva: Universidad de Huelva. Disponible en: http://rabida.uhu.es/dspace/handle/10272/2648

Cuenca, J. M. (2014). El papel del patrimonio en los centros educativos: hacia la socialización patrimonial. Tejuelo (19), 76-96.

Cuenca, J. M. y Estepa, J. (2006). La mirada de los maestros, profesores y gestores del patrimonio: investigación sobre concepciones acerca del patrimonio y su didáctica. En R. Calaf y O. Fontal (Coords.). Miradas al patrimonio (pp. 51-71). Gijón: Trea. 
Decreto-Ley 97/2015, de 3 de marzo, por el que se establece la ordenación y el currículo de la Educación Primaria en Andalucía. Boletín Oficial de la Junta de Andalucía, 3 de marzo de 2015 (50), 21-22.

Estepa, J. (2001). El patrimonio en la didáctica de las Ciencias Sociales: obstáculos y propuestas para su tratamiento en el aula. Iber. Didáctica de las Ciencias Sociales, Geografía e Historia (30), 93-105.

Fernández Salinas, V. (2005). Finalidades del patrimonio en la educación. Investigación en la escuela, 56, 7-18.

Ferreras Listán, M. (2013). La Educación Patrimonial en los libros de texto de Conocimiento del Medio de Educación Primaria. En J. Estepa (Coord.). La educación escolar en la escuela y el museo: investigación y experiencias (pp. 215-223). Universidad de Huelva: Servicio de publicaciones.

Fontal, O. y E Ibáñez, A. (2015). Estrategias e instrumentos para la educación patrimonial en España. Educatio Siglo XXI, 33 (1), 15-32.

García, S. (2014). Educación patrimonial, un proyecto de inclusión. Monográfico (9), 9-19.

Gardner, H. (2001). La inteligencia reformulada. Barcelona: Paidós.

González Monfort, N. (2007). L'ús didàctic i el valor educatiu del patrimoni cultural. Barcelona: Universidad Autónoma de Barcelona. Disponible en: http://www.tesisenred.net/bitstream/handle/10803/4673/ngm1de1.pdf?sequence=1.

Ibáñez, A.; Fontal, O. y Cuenca, J. M. (2015). Actualidad y tendencias en Educación Patrimonial. Educatio Siglo XXI, 33 (1) 11-14.

Hernández Cardona, F.X. (2003) El patrimonio como recurso en la enseñanza de las Ciencias Sociales. En:E. Ballesteros y otros (Eds.) El patrimonio y la Didáctica de las Ciencias Sociales (pp. 455-466). Cuenca: Asociación Universitaria de Profesores de Didáctica de las Ciencias Sociales.

Ibáñez, A.; Fontal, O. y Cuenca, J. M. (2015). Actualidad y tendencias en Educación Patrimonial. Educatio Siglo XXI, 33 (1), 11-14.

Jiménez, R.; Cuenca, J. M. y Ferreras, M. (2010). Heritage education: exploring the conceptions of teachers and administrators from the perspective of experimental and social science teaching. Teaching and Teacher Education, 26 (6), 1319-1331.

Llobet, C. y Valls, C. (2003). El patrimonio como recurso en la enseñanza de las Ciencias Sociales en Educación Primaria. Universitat Autónoma de Barcelona. En:E. Ballesteros et al. (Coord.), El Patrimonio en la Didáctica de las Ciencias Sociales (pp. 467-473). Cuenca: Cuenca: Asociación Universitaria de Profesores de Didáctica de las Ciencias Sociales.

Marín, S., García, S., Vicent, N., Gillate, I. y Gómez, C. (2017). Educación Patrimonial Inclusiva en OEPE: un estudio prospectivo. Revista de Educación, 375, 110-135.

Marín, S. (2014). Educación patrimonial y diversidad: evaluación de programas y definición de un modelo basado en los proyectos de patrimonialización. Disponible en: http://uvadoc.uva.es/bitstream/10324/7416/1/TESIS601-141204.pdf.

Marín, S. (2014). Relaciones entre inclusión social, accesibilidad y patrimonio cultural. La educación como clave. En A. Domínguez, J.G. Sandoval y P. Lavado, En y con todos los sentidos: hacia la integración social en igualdad. Actas de II Congreso Internacional de Educación y Accesibilidad. Museos y Patrimonio. Universidad de Zaragoza. Máster en museos: educación y comunicación. Huesca, España.

Martín, M. J. y Cuenca, J. M. (2015). Educomunicación del patrimonio. Educatio Siglo XXI, 33 (1), 3354.

Melgar, M., \& Donolo, D. (2011). Salir del aula. Aprender de otros contextos. Patrimonio natural, museos e Internet. Revista Eureka Sobre Enseñanza Y Divulgación De Las Ciencias, 8 (3), 323-333.

Miedes, B., Sánchez, C., Moreno, A. (2014). Escenarios alternativos para las TICS y el conocimiento territorial en el marco de las transiciones socioecológicas: smart cities e inteligencia territorial. ¿Hacia una sociedad del "buen conocer"? En A.L. Hidalgo y M.O. Barroso (Presidencia), 
Perspectivas alternativas del desarrollo. II Congreso Internacional de Estudios del Desarrollo. Universidad de Huelva, España.

Orden, de 17 de marzo de 2015, por la que se desarrolla el currículo correspondiente a la Educación Primaria en Andalucía.

Orden ECD/65/2015, de 21 de enero, por la que se describen las relaciones entre las competencias, los contenidos y los criterios de evaluación de la Educación Primaria, la Educación Secundaria Obligatoria y el Bachillerato. Boletín Oficial del estado, de 29 de enero de 2015, (25), 1-18.

Pablos, L. Y Fontal, O. (2018). Educación patrimonial orientada a la inclusión social para personas con TEA: los museos capacitantes. Arteterapia. Papeles de arteterapia y educación para inclusión social, (13), 33-52.

Peñalba, J. L. (2010). Jugar en sitios históricos: dos experiencias de educación en el tiempo libre e interpretación del patrimonio en Alcalá de Henares. Pulso: Revista de Educación, (33), 131-153.

\section{Información sobre las autoras}

Autora: Elisa Arroyo Mora

Institución: Universidad de Huelva

Email: elisa.arroyo@ddi.uhu.es

ORCID: 0000-0001-9724-5415

Autora: Belén Crespo Torres

Institución: Universidad de Huelva

Email: belen.crespo@ddi.uhu.es

ORCID: 0000-0003-1344-4818 


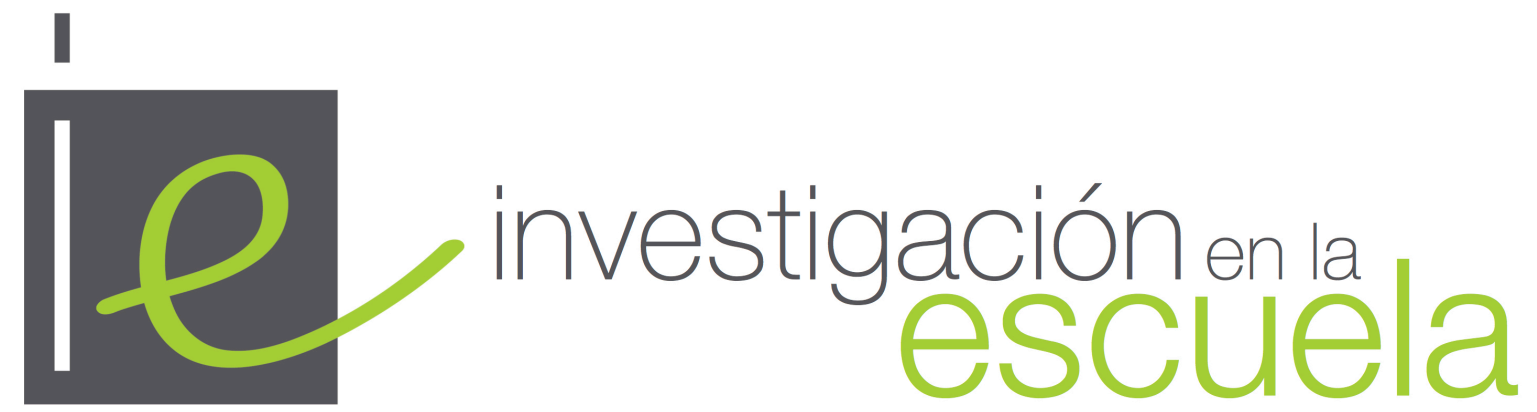

Revista académica evaluada por pares y de acceso abierto

Número 98

31 de julio de 2019

ISSN 2443-9991

\section{(c) (i) (2)}

Esta obra está bajo una licencia Creative Commons. Los/as lectores/as pueden compartir, copiar y redistribuir el material en cualquier medio o formato, así como adaptar, remezclar, transformar y construir a partir del material para cualquier propósito, incluso comercialmente. Para ello, deben de hacerlo bajo los siguientes términos: dando crédito de forma adecuada, brindando un enlace a la licencia e indicando si se han realizado cambios. Si se remezcla, transforma o crea a partir del material, debe distribuir su contribución bajo la misma licencia del original.

Más detalles de la licencia de CreativeCommons se encuentran en https://creativecommons.org/licenses/by-sa/4.0/deed.es

Cualquier otro uso debe ser aprobado en conjunto por el autor/es, o Investigación en la Escuela.

ư

Revista Editada por la Universidad de Sevilla. https://editorial.us.es/es/revistainvestigacion-en-la-escuela

Por errores y sugerencias contacte a secretaria@investigacionenlaescuela.es

La revista Investigación en la Escuela desde su origen en 1987 hasta su no 87 (2015) fue editada por Díada Editora. 
